\title{
150 anos da Guerra do Paraguai: projetos, comemorações e apropriações em torno da retirada da Laguna
}

150th anniversary of the War of Paraguay: projects, celebrations and appropriations around the Laguna Withdrawal

150 aniversario de la Guerra de Paraguay: proyectos, celebraciones y apropriaciones de la Retirada de Laguna

Ana Paula Squinelo* Jérri RobertoMarin ${ }^{* *}$

\section{Resumo}

Este trabalho trata do sentido das comemorações acerca da Guerra do Paraguai (1864-1870), em Mato Grosso e Mato Grosso do Sul. Para tal, nos reportamos aos debates concernentes à memória, aos espaços da memória e às comemorações. Especialmente, elencamos como eixo norteador de nossas reflexões o episódio denominado retirada da Laguna (18651867), considerado cenário secundário da Guerra do Paraguai e ocorrido em território mato-grossense. Interessa-nos, sobretudo, refletir sobre os impactos desse evento na constituição da memória e da identidade sul-mato-grossense.

Palavras-chave: Comemorações. Guerra do Paraguai. Retirada da Laguna.
Analisamos neste artigo os sentidos das comemorações sobre a Guerra do Paraguai (1864-1870), sobretudo em relação ao episódio da retirada da Laguna (1865-1867), em Mato Grosso e em Mato Grosso do Sul. O objetivo é refletir sobre as apropriações e reapropriações desse evento na constituição da memória e da identidade sul-mato-grossense. A construção

* Doutora em História Social pela Universidade de São Paulo - USP. Professora associada da Universidade Federal de Mato Grosso do Sul - UFMS. Coordenadora do Laboratório de Ensino de História e do grupo de pesquisa Historiografia e Ensino de História. E-mail: apsquinelo@yahoo.com.br

* Doutor em História pela Universidade Estadual Paulista - Unesp. Professor associado da Universidade Federal de Mato Grosso do Sul. Professor da Pós-Graduação em História da Universidade Federal da Grande Dourados - UFGD. E-mail: jerrimarin@bol.com.br

Recebido em 06/04/2015 - Aprovado em 02/06/2015 http://dx.doi.org/10.5335/hdtv.15n.2.5648 
de uma história oficial de heróis e datas celebrativas, de monumentos para Mato Grosso e para Mato Grosso do Sul, estado criado em 1977, valorizou o episódio da retirada da Laguna. Mais recentemente, o projeto Trilha da Retirada da Laguna reafirmou a importância desse evento e indicou novas formas de apropriação por várias instituições e pelo Estado.

Pierre Nora (1993), ao refletir sobre o bicentenário da Revolução Francesa, constatou que existia uma obsessão comemorativa que se manifestava na transformação de todas as datas históricas em eventos celebrativos. As comemorações são lugares de memória, definidas como:

[...] toda a unidade significativa, de ordem material ou ideal, da qual a vontade dos homens ou o trabalho do tempo fez um elemento simbólico do patrimônio da memória de uma comunidade qualquer (NORA, 1993, p. 20).

\section{O autor ainda apontou que:}

Os lugares de memória são, antes de tudo, restos. A forma extrema onde subsiste uma consciência comemorativa numa história que a chama, porque ela a ignora. É a desritualização de nosso mundo que faz aparecer a noção. O que secreta, veste, estabelece, constrói, decreta, mantém pelo artifício e pela vontade uma coletividade fundamentalmente envolvida em sua transformação e sua renovação. Valorizando, por natureza, mais o novo do que o antigo, mais o jovem do que o velho, mais o futuro do que o passado. Museus, arquivos, cemitérios e coleções, festas, aniversários, tratados, processos verbais, monumentos, santuários, associações, são os marcos testemunhas de uma outra era, das ilusões e da eternidade. [...] sinais de reconhecimento e de pertencimento de grupo numa sociedade que só tende a reconhecer os indivíduos iguais e idênticos.
Os lugares de memória nascem e vivem do sentimento que não há memória espontânea, que é preciso manter aniversários, organizar celebrações, pronunciar elogios fúnebres, notariar atas, porque essas operações não são naturais (1993, p. 12-13).

As comemorações são eventos de grande potencial simbólico quando o Estado, as instituições e a sociedade civil repensam o passado e o presente e elaboram projetos para o futuro. Os Estados nacionais, nos séculos XIX e XX, inventaram tradições, criaram cerimônias públicas, construíram monumentos públicos e um passado comum, supostamente imemorial, para legitimarem-se e robustecer os sentimentos religiosos e cívicos. Para Hobsbawm, muitas tradições, como as comemorações das datas pátrias e os símbolos nacionais, são invenções recentes, ou seja, um "conjunto de práticas [...], de natureza ritual ou simbólica, que buscam inculcar certos valores e normas de comportamento" (HOBSBAWM; RANGER, 1994, p. 9). Os símbolos nacionais e os monumentos eternizam a data da fundação da nação, criam uma memória nacional e motivam o entusiasmo cívico. Ou seja, os festejos cívicos têm pretensões comemorativas e pedagógicas, pois constroem subjetividades.

Segundo Connerton,

[...] as nossas experiências do presente dependem, em grande medida, do conhecimento que temos do passado e que as nossas imagens desse passado servem normalmente para legitimar a ordem social presente (1999, p. 2).

Como parte do esforço das sociedades em manter uma relação profícua com o passado, o autor apontou a necessidade de se 
instituir e preservar os rituais, que seriam responsáveis pela contiguidade com o passado, seja remoto ou imediato.

Tendo em vista tais apontamentos acreditamos que a retirada da Laguna constituiu-se em um dos episódios a ser meticulosamente preservados no contexto da história do Brasil, de Mato Grosso e de Mato Grosso do Sul. Interessante ressaltar que os acontecimentos em torno da retirada, embora tenham se centralizado em solo mato-grossense, despertaram comoção nacional. O episódio é considerado como o mais glorioso da história militar e do Exército brasileiro, como uma epopeia patriótica caracterizada pela constância, pela disciplina militar, pela resignação, pelo heroísmo e pelo valor dos combatentes, pois conseguiram retornar com todos os canhões e bandeiras (CARDOSO, 2011, p. 17-22). Como decorrência, é (re) memorado não só regionalmente como também nacionalmente.

Alfredo Maria Adriano d'Escragnolle Taunay participou como protagonista na Guerra do Paraguai, no episódio que ficou conhecido por retirada da Laguna. Atuou como ajudante da comissão de engenheiros das forças que foram destinadas ao sul de Mato Grosso entre os anos de 1865 e 1867. Taunay ingressou na coluna aos 25 anos de idade, e presenciou grande parte das cenas desencadeadas no teatro de operações. Sobrevivendo à longa marcha, retornou ao Rio de Janeiro, onde, por insistência de seu pai, começou a escrever a obra que viria imortalizar a grande tragédia a que esteve submetido o exército brasileiro: A retirada da Laguna: episódio da Guerra do Paraguai.
Taunay confessou que escreveu a obra por pressão do pai, e que a teria escrito em "vinte e poucos dias". A obra, assim como Cenas de viagem, foi recebida com desinteresse pelo seu círculo de amigos, exceto pelo Conde D`Eu (TAUNAY, 1983, p. 303). A primeira versão de A retirada da Laguna data de 1868 e continha pouco mais de 50 páginas, a versão integral é datada de 1871. A primeira tradução para o português foi realizada em 1874 por Salvador de Mendonça. Porém, foi a tradução de Ramiz Galvão, de 1915, a mais difundida. Cabe ressaltar que a obra foi traduzida para diversos idiomas e, no Brasil, podemos anotar inúmeras reedições. Ela é considerada como uma obra representativa do fim do Romantismo e do início do Realismo e um clássico da literatura, ao lado de $O s$ sertões, de Euclides da Cunha (2000).

Com a cristalização de $A$ retirada da Laguna: episódio da Guerra do Paraguai, iniciou-se a construção épica da historiografia que aborda esse tema. Segundo Cardoso, é a obra mais editada e lida, no Brasil, sobre as operações militares na Guerra do Paraguai e que, desde a década de 1930, vem sendo adaptada em histórias em quadrinhos, revistas, livros e álbuns. O objetivo de traduzir a obra para outras linguagens era difundir o patriotismo brasileiro, tais como os sentimentos de "abnegação, persistência, amor à pátria e coragem". Artistas plásticos utilizaram a obra como fonte para compor pinturas épicas sobre a Retirada (CARDOSO, 2011, p. 20). O filme Alma do Brasil, ${ }^{1}$ produzido na década de 1930, teve cenas filmadas nos locais dos acontecimentos.

Entre 1867 e 1868, Taunay publicou outras obras sobre a guerra, por exemplo, 
Scenas de viagem e Relatório geral da comissão de engenheiros, que foi elaborado no percurso da campanha de Mato Grosso. Em 1869, quando o Conde d'Eu, genro de Dom Pedro II, assumiu o comando das forças brasileiras em operação no Paraguai, Taunay retornou ao teatro de operações como secretário do estado-maior. Terminada a guerra, em 1870, ele retornou ao Rio de Janeiro. Resultou dessa experiência a publicação de Diário do Exército, em que descreveu a ocupação do Paraguai e a morte de Francisco Solano López. Outras obras que registram sua presença em solo mato-grossense são: Campanha de Mato Grosso, Dias de guerra e de sertão, Cartas da campanha de Mato Grosso, 1865-1866, Céus e terras do Brasil, Viagens de outrora, Paisagens brasileiras, Diário do exército (1869-1870), A campanha da cordilheira, De Campo Grande a Aquidabã, Em Mato Grosso invadido (18661867) e Visões do sertão.

Embora Taunay tenha participado de duas fases da campanha da Guerra do Paraguai, pouco esteve presente nos combates. Segundo Alambert, o engenheiro "nunca se apresenta trabalhando. Ele não é nem mesmo o 'nobre-guerreiro'" (1999, p. 39). Taunay apenas:

[...] estuda, observa com seu binóculo racional, escreve, corrige e anota os dilemas da moralidade, buscando colocá-los na balança dos trunfos que podem vir a construir a civilização brasileira $(1999$, p. 39).

A narrativa de $A$ retirada da Laguna está centrada em dois eixos temáticos: primeiro, o despreparo e as improvisações do exército, o desentendimento entre os oficiais superiores a inexistência de uma logística, de armamentos, de oferta de suprimentos (água e alimentos), de controle sanitário, de assistência aos doentes e feridos e, também, o pouco treinamento dos soldados. Essas deficiências já estavam presentes durante as ações da coluna expedicionária e durante sua retirada; segundo, o desconhecimento geográfico do território mato-grossense e paraguaio e a inexistência de mapas da região. A grande extensão territorial e sua exuberância justificavam e atenuavam a derrota.

A obra deve ser compreendida dentro do contexto da sua produção. Primeiramente, Taunay não era somente um homem ligado às estruturas imperiais, como também as defendia arduamente. Por isso, procurou assegurar tanto a integridade do Império, como também a instituição à qual pertencia ao imortalizar os grandes feitos do exército brasileiro. Ou seja, Taunay foi um homem que viveu a consolidação, glória e desestruturação do Império brasileiro, e sua família sempre manteve estreitos laços com o Estado. Na obra, Taunay assumiu o fracasso da coluna, entretanto, narrou o episódio de forma romântica, épica e honrosa. Assim, o que se constituiu em um fracasso para o exército brasileiro adquiriu, nas sucessivas páginas de sua obra, outra dimensão, qual seja, a do patriotismo, da glória, da honra, da defesa e da entrega pela pátria. $\mathrm{O}$ atento leitor passará por suas páginas com o sentimento de que, por mais adversidades que a coluna tenha enfrentado, acabou por derrotar os paraguaios, alcançou Nioaque e cumpriu seu dever para com a pátria. Forjavam-se, dessa forma, heróis nacionais, datas a serem comemoradas e uma história patriótica repleta de feitos grandiosos.

Também compõem a obra lembranças e anotações que Taunay registrava em um 
diário de campanha que fazia parte de suas obrigações profissionais. Ou seja, o texto não foi produzido no "calor dos acontecimentos". Ao recompor suas lembranças, esteve sujeito às falhas a que o substrato da memória nos expõe, mas, ao mesmo tempo, o contexto propiciou que a remontasse de acordo com aquilo que queria preservar e registrar em seus escritos.

A credibilidade do relato de suas obras não é atribuída somente ao volume de fontes, às anotações do seu diário de campo, aos argumentos e às interpretações, mas ao fato de ele ter estado lá, o que certifica, por escrito, o testemunho único de situações presenciadas e vividas. $\mathrm{O}$ texto escrito consagra interpretações, representações, imagens da alteridade e de interesses políticos, ao mesmo tempo em que, sempre, denuncia a presença de Taunay como autor, seus recortes e suas escolhas. Além disso, as imagens que produziu acerca do antigo Mato Grosso estão afinadas com as discussões e teorias científicas desenvolvidas durante o XIX: civilização versus barbárie; modernidade versus atraso; intempéries versus natureza ou progresso versus civilização.

\section{A construção de memórias em torno da} retirada da Laguna em Mato Grosso e no Brasil

A Guerra do Paraguai marcou sobremaneira o processo histórico mato-grossense e brasileiro. A obra A retirada da Laguna contribuiu para inserir Mato Grosso no imaginário nacional, como o outro geográfico da nação. Seria uma fronteira-sertão ainda não incorporada à nacionalidade, em que a presença do Estado deveria ser consolidada.
Como decorrência, acabou por levar o governo imperial a voltar seu olhar ao então "abandonado" e "desprotegido" Mato Grosso, ao reabrir o porto de Corumbá, ao definir as fronteiras com o Paraguai e alargar o território brasileiro, ao construir a ferrovia Noroeste do Brasil e uma rede de telégrafos integrando a região, ao acelerar o processo migratório; e, por último, ao imortalizar o episódio da retirada da Laguna, que passou a fazer parte da memória da região, como também justificou a escrita de uma história mato-grossense ligada aos desígnios de uma elite dominante. Conforme Zorzato (1998), o discurso memorialista construído ao longo do século XX pelos intelectuais mato-grossenses sempre esteve atrelado aos grupos que disputavam e partilhavam o poder, dando-lhes, principalmente, legitimidade.

Em Mato Grosso, a retirada da Laguna passou a ser valorizada no contexto das comemorações do bicentenário da fundação de Cuiabá, em 1919. Essas se tornaram referências para as construções de novas identidades e centralizaram-se em torno das manifestações culturais de exaltação à terra $\mathrm{e}$ ao homem mato-grossense. D. Francisco de Aquino Corrêa, então presidente do Estado, fundou duas instituições que investiram na produção simbólica para redefinir a identidade regional: o Instituto Histórico e Geográfico de Mato Grosso, em 1919, e o Centro Matogrossense de Letras, em 1921. Para as comemorações, foram elaboradas poesias, canções patrióticas, símbolos distintivos da identidade regional, como o brasão de armas (1918), o hino mato-grossense (1918) e a confecção da carta geográfica de Mato Grosso. O brasão, o hino, as canções e poemas e 
as publicações oficiais reforçavam inúmeros valores e exaltavam o homem, a natureza, o passado heroico, a união entre os mato-grossenses e a inevitabilidade do progresso.

A divisa latina do Instituto Histórico Pro Pátria cognita atque immortali (Pela pátria conhecida e imortal) trazia a lume as preocupações em preservar, divulgar e imortalizar a memória e as tradições culturais regionais, e inseri-las na história brasileira. Desejava-se superar o estigma da barbárie e incivilidade ao divulgar um discurso legítimo e "verdadeiro" sobre o Mato Grosso, assegurando assim um espaço privilegiado na história do Brasil. Para D. Aquino Corrêa, construir uma história oficial era, acima de tudo, exaltar e glorificar o Mato Grosso e os feitos dos mato-grossenses.

A versão mitificada da história e a eleição de um panteão cívico buscavam salientar figuras que serviriam de modelos e arquétipos para os valores e aspirações coletivas, além de reforçar identidades e orientar ações e projetos concretos. Entre os heróis eleitos estavam os bandeirantes paulistas, os participantes da Guerra do Paraguai e, por fim, mato-grossenses tidos como portadores de qualidades atávicas. Entre as imagens mobilizadas estavam o grande número de descendentes, ainda vivos, de José Francisco Lopes, o guia Lopes, um dos heróis eleitos para o panteão cívico mato-grossense. Seus descendentes eram apontados como provas visíveis do passado heroico. Como herói, o guia Lopes servia de modelo de patriotismo e conferia um lugar de destaque aos mato-grossenses na história nacional, principalmente na vitória na Guerra do Paraguai e na defesa e ampliação da fronteira oeste.
Na perspectiva oficial, Mato Grosso, desde sua incorporação ao Brasil, teria demonstrado historicamente sinais de civismo e brasilidade. A incorporação, pelos bandeirantes, das terras que posteriormente constituiriam o Mato Grosso era vista como afirmação da nacionalidade e obra exclusivamente brasileira. A brasilidade dos mato-grossenses poderia ser atestada na ampliação das fronteiras a oeste, na vitória da Guerra do Paraguai, na defesa dos 3 mil quilômetros de fronteiras geográficas com a Bolívia e o Paraguai (apesar da rarefação demográfica e do pequeno apoio governamental), na "obra civilizadora" de ocupação territorial, pela incorporação do indígena à civilização e por priorizar os interesses nacionais sobre os regionais (refere-se à cessão de parte do território de Mato Grosso à Bolívia, no Tratado de Petrópolis, em 1903).

Enfim, na perspectiva da história oficial, Mato Grosso seria o estado mais brasileiro do Brasil, embora fosse uma das últimas regiões a se integrar ao seio da nacionalidade. Brasilidade, catolicidade, bravura, determinação e patriotismo seriam os valores fundamentais dos mato-grossenses. Corrêa Filho destacou o papel dos mato-grossenses no conflito, as "angústias" frente à ocupação paraguaia, a proliferação de epidemias e a "recuperação" de Mato Grosso. A retirada foi considerada uma epopeia, "imortalizada na 'Retirada de Laguna', escrita por Taunay, que participou dos padecimentos dos expedicionários e lhes testemunhou os lances gloriosos de heroísmo" (1969, p. 548-549).

A valorização da retirada da Laguna também ocorreu em nível nacional. No início da década de 1920, setores da sociedade, 
sobretudo os militares, procederam a uma intensa campanha para comemorar e recuperar a memória em torno desse episódio e da memória dos heróis Cel. Carlos de Moraes Camisão, Antônio João, José Francisco Lopes, o guia Lopes, e incluía também a lembrança do Visconde de Taunay. Por iniciativa dos alunos da Escola Militar do Rio de Janeiro foi construído o monumento Aos Heroes de Laguna e de Dourados, situado na Praia Vermelha, naquela cidade. O projeto vencedor intitulado Veritas et labor, do escultor Antonio Pinto de Mattos, tinha uma estética monumentalista e homenageava os principais protagonistas da retirada. A construção do monumento mobilizou diferentes setores da sociedade brasileira que se empenharam para que as comemorações ocorressem em nível nacional. Entre as iniciativas estava a construção de monumentos em Mato Grosso, mais especificamente em Nioaque e Aquidauana, em 1923, construídos com verbas do Ministério do Exército destinadas a edificações militares (SQUINELO, 2006, p. 115). Também como parte das comemorações e rememorações da retirada da Laguna foi construído o Panteão em homenagem ao Duque de Caxias, no Rio de Janeiro.

A notícia da construção de um monumento em Nioaque e do interesse em instalá-lo em Campo Grande levou o intendente Arlindo de Andrade Gomes a persuadir o ministro da guerra com o argumento de ser a cidade o maior centro de atividade do Estado, pois a população do sul de Mato Grosso deslocava-se para o município por motivos de saúde, estudos e para o comércio. Ele arrolou ainda outros fatores: a) o fato de a cidade estar ligada por rodovias e pela ferro- via Noroeste do Brasil; $b$ ) as ruas e os logradouros da cidade homenageiam os heróis da guerra: ruas Visconde de Taunay, Cel. Carlos de Moraes Camisão, José Francisco Lopes (o guia Lopes), Antônio João, e pela Praça Retirada da Laguna; c) o conhecimento cívico que os moradores tinham da história da Guerra do Paraguai; d) por ter várias escolas, despertaria na mocidade o amor à Pátria, ao venerar os seus monumentos, adorando-a em dias de festas, guardando-a com carinho; e) o fato de residirem na cidade quarenta descendentes de guia Lopes.

A municipalidade iria auxiliar financeiramente a instalação na Praça da República, no centro da cidade, e comprometeu-se em embelezá-la com jardins e "outras decorações". Por fim, Arlindo de Andrade Gomes afirmava que o monumento seria mais bem interpretado em Campo Grande do que em outra cidade. ${ }^{2}$ Porém, o monumento foi instalado em Nioaque, em 1923.

A partir da década de 1930, o dia de Santo Antônio, padroeiro da cidade, passou a ser comemorado com eventos militares e cívicos que homenageavam o episódio da retirada da Laguna e os seus principais personagens. A solenidade era festejada com uma parada militar, da qual participavam as escolas católicas, seguidas do juramento à bandeira nacional dos novos militares do Comando da $9^{a}$ Região Militar. Os limiares entre catolicidade e brasilidade eram tênues, pois ao lado dos símbolos católicos desfilavam os nacionais e os regionais, assim como o culto de Santo Antônio com o dos heróis mato-grossenses e brasileiros.

Posteriormente, outros monumentos foram construídos em Mato Grosso, sobre- 
tudo durante governos autoritários e nacionalistas. Getúlio Vargas, durante o Estado Novo (1937-1945), institucionalizou o culto aos heróis e aos episódios da retirada da Laguna que se caracterizavam como sinônimos de nossa brasilidade.

Como exemplo [nesse período], cite-se a importância dada à educação moral e cívica, à revalorização das entradas e bandeiras para o interior, à construção da categoria sertão, da ideia de "trabalhador novo", "homem novo", etc. (SANTOS, 1996, p. 94).

Representando esse período, apontamos a construção de monumentos em Bela Vista, em 1931, e em Coxim, em 1941, esse último erigido pela $9^{a}$ Região Militar. Outro momento de valorização da retirada da Laguna foi durante a ditadura militar (19641985), em que foi instituído pelo Exército brasileiro o período de 12 de novembro de 1964 a $1^{\circ}$ de março de 1970 como marco comemorativo do centenário da Guerra do Paraguai. Em Mato Grosso, o centenário da Guerra foi comemorado entre os dias 15 e 20 de junho de 1970. A $9^{a}$ Região Militar, a $4^{\text {a }}$ Divisão de Cavalaria, prefeitos, autoridades, escolas e população em geral homenagearam os heróis da Laguna com placas comemorativas fixadas nos municípios de Aquidauana, Miranda e Nioaque (SQUINELO, 2006, p. 119).

Squinelo (2006, p. 147-148) analisou dezesseis monumentos construídos em Mato Grosso, que foram classificados em cívico, cívico funerário e funerário patriótico. Cada um com estilos e referências próprias, de acordo com o período histórico, recursos econômicos investidos em sua confecção e de acordo com as concepções estéticas de quem os projetou. Os monumentos cívicos caracterizam-se pela sua simplicidade, pela lembrança que trazem de determinado acontecimento e por serem laicos, como o caso do monumento de Coxim e Miranda; os monumentos cívicos funerários relembram a abnegação, seguida do sacrifício e da morte. Localizados sobretudo nos cemitérios e igrejas, eles relembram o sacrifício dos mortos, como os monumentos de Jardim e Bela Vista; os monumentos funerários patrióticos relembram e glorificam principalmente o sacrifício pessoal em favor da pátria.

Oito monumentos possuem inscrições que homenageiam episódios e as "glórias imortais dos heróis" da Guerra do Paraguai, como o da retirada da Laguna, o da colônia militar de Dourados e o da retomada de Corumbá - localizados no Parque Histórico da Colônia Militar de Dourados e nos municípios de Aquidauana, Bela Vista, Corumbá, Coxim, Jardim, Miranda e Nioaque. Seis monumentos rememoram o primeiro centenário da Guerra do Paraguai e se encontram em Aquidauana, Bela Vista, Jardim, Miranda, Nioaque e no Parque Histórico da Colônia Militar de Dourados. Seis monumentos apresentam inscrições que homenageiam Antônio João, eleito herói e mártir da nação brasileira, símbolo de bravura e patriotismo. Esses monumentos estão em Antônio João, Aquidauana, Bela Vista, Corumbá, Dourados e no Parque Histórico da Colônia Militar de Dourados. Dois monumentos fazem referência aos oficiais da retirada da Laguna, destacando suas qualidades como intrépidos e beneméritos; situam-se em Coxim e Jardim e homenageiam oficiais e praças - Cel. Carlos de Moraes Camisão e TC. Ju- 
vêncio M. Cabral de Menezes -, considerados intrépidos e valentes. Dois monumentos construídos pelo Exército destacam o episódio da retirada e localizam-se em Jardim e Nioaque. O primeiro monumento traz a seguinte inscrição: "Retirada da Laguna. A 4 a Bda CMEC realizou no período de 13 a 20 de julho de 99 a primeira marcha cívico-cultural a pé, percorrendo $223 \mathrm{~km}$ entre Bela Vista - Nioaque e vivenciando as efemérides do Visconde de Taunay e o fato histórico retirada da Laguna". O segundo caracteriza a reconstituição daqueles sucessos, com as informações: "Retirada da Laguna. Revivida a pé, pela $4^{a}$ Bda CMEC - 'Brigada Guaicurus', suas OMDS e convidados especiais [...]" (SQUINELO, 2006, p. 147-148).

A memória da Guerra do Paraguai e da retirada da Laguna pode ser constatada, ainda, em ruas, avenidas, prédios públicos, escolas, parques e cemitérios, de diferentes cidades de Mato Grosso do Sul (Antônio João, guia Lopes da Laguna e, indiretamente, Inocência). O aeroporto internacional de Campo Grande homenageia Antônio João. Também foram instituídas ações comemorativas como a Semana dos Heróis do Forte de Coimbra e da Colônia Militar de Dourados, que ocorreu em dezembro de 1964. O município de Nioaque celebra todos os anos sua fundação na Praça dos Heróis e, desde 2013, organiza o Festival Retirada da Laguna.

Nesse sentido, evidenciamos que as sociedades recordam seus feitos passados de inúmeras formas, resguardando suas tradições e criando outras, conforme apontado por Hobsbawm e Ranger (1994), ao registrar, criar e recriar tanto sua história, como sua memória. Porém, os monumentos
[...] traduzem as intenções dos municípios da época. Com o tempo, os cidadãos podem ter-lhe dado um sentido diferente [...]. As cerimônias cujos monumentos foram o centro de interesse podem tê-los revestidos de significações que não tinham na época (PROST, [19--?], p. 196).

Por fim, qual o sentido que conservam ou renovam os monumentos em meio às transformações da cidade e da sociedade? Nas paisagens urbanas contemporâneas os monumentos perdem, cada vez mais, a função de legitimar o culto tradicional. Ao serem idealizados, as suas dimensões gigantescas e a instalação em espaços centrais contribuíam para enaltecer e consagrar os heróis e os acontecimentos fundadores do Estado por meio da ritualidade das cerimônias cívicas e das liturgias autoconsagradoras do poder (CANCLINI, 1998, p. 291).

Nas tramas das cidades contemporâneas, as tensões entre memória histórica e a trama visual se acirraram. Como decorrência, esses espaços de memória perdem suas significações e podem ser apropriados de outras formas, diferentes daquelas idealizadas pelos que os projetaram. Alguns se perdem em meio aos sinais de trânsito, aos banheiros públicos, ao mato, a campos de futebol, a praças públicas, a árvores e em meio aos signos políticos e comerciais. Festas e manifestações públicas ocorrem nesses locais, com diferentes intenções que extrapolam o nacionalismo e o culto aos heróis. Inúmeros moradores das cidades em que estão localizados os monumentos desconhecem sua existência ou o contexto histórico homenageado. Muitos dos monumentos enumerados estão em estado de abandono e são alvo de depredações. Espaços públicos que homenageavam 
episódios históricos relativos à Guerra do Paraguai deixam de existir, como a Praça da Retirada da Laguna, em Campo Grande.

Contudo, de outro modo, os monumentos se renovam "ao dialogar com as contradições presentes" da vida urbana e "por meio das 'irreverências' dos cidadãos". Os grafites e as manifestações sociais e políticas expressam a crítica à ordem imposta, enquanto cartazes comerciais e outdoors sincronizam a vida econômica com os interesses do poder econômico (CANCLINI, 1998, p. 301-302). Segundo Canclini,

[...] a proliferação de anúncios sufoca a identidade histórica, dissolve a memória na percepção ansiosa das novidades incessantemente renovadas pela publicidade (1998, p. 302).

\section{A retirada da Laguna em Mato Grosso do Sul: projetos, comemoraçoes} e apropriações

Com a divisão do Estado (Mato Grosso e Mato Grosso do Sul), efetivada em 1979, Mato Grosso do Sul ficou órfão de história. Na busca de construir sua identidade e seu passado, procedeu-se a uma escrita que privilegiou, como já pontuado, entre outros aspectos, a Guerra do Paraguai, sobretudo a retirada da Laguna, para compor a memória que se desejava preservar. Tal fato explica-se, ao menos em parte, pelo desejo de possuir uma história ligada aos eventos regionais e nacionais.

A divisão de Mato Grosso, com a criação, em 1977, de Mato Grosso do Sul, trouxe vários desafios ao Estado, bem como às instituições, às elites regionais, aos diferentes grupos sociais e aos indivíduos engajados na- quele processo. Era necessário criar uma nova região, com recortes geográficos, políticos e culturais, e sobretudo criar uma identidade regional e sentimentos de pertença coletiva. O Estado mobilizou instituições, grupos e intelectuais, de diferentes campos, a fim de forjarem a identidade sul-mato-grossense. Para esse fim, foram criadas duas instituições, a Academia Sul-Matogrossense de Letras, fundada desde 1972, e o Instituto Histórico e Geográfico de Mato Grosso do Sul (IHGMS), criado em 1978. Também foi criada, em 1984, a Fundação de Cultura, pelo governador Wilson Barbosa Martins. Para a presidência foi nomeado José Octávio Guizzo, um advogado envolvido com o projeto de construção da identidade regional no campo artístico. A elite regional foi tecendo, paulatinamente, uma história, heróis, datas cívicas, artes plásticas, patrimônio histórico, cinema, e uma música que sintetizasse a alma do sul-mato-grossense. Para isso, mato-grossenses foram transformados em sul-mato-grossenses.

O IHGMS, ao ser fundado, tinha trinta membros, que pertenciam à elite econômica, política e cultural, e tinha como presidentes de honra aqueles que seriam os futuros governadores de Mato Grosso do Sul, estabelecendo, dessa forma, vínculos da entidade com o governo estadual. Segundo Squinelo, "[...] a memória em pauta a ser conservada [prendia-se] justamente a uma elite que [tinha] como objetivo a idealização de um passado grandioso" (2002, p. 72), e também divulgar o futuro promissor do novo Estado, engrandecendo-o diante dos demais. Dessa forma, legitimavam a divisão proposta de forma autoritária pelo governo de Ernesto Geisel. Enfim, a construção discursiva da região ficou aprisionada pelo dispositivo 
oficial, pelo discurso da identidade, pela preocupação com o resgate das raízes, do patrimônio e pelo engajamento na criação de sentimentos de pertenças coletivos.

Segundo Squinelo, as diversas obras publicadas após a criação do estado de Mato Grosso do Sul apresentam várias características comuns:

1) trazem, em um primeiro momento, uma descrição geográfica da região, com ênfase nos seus rios, na fauna, na flora, no clima, etc.; 2) apontam os primeiros homens que devassaram o território e a disputa entre portugueses e espanhóis pela posse do mesmo; 3) abordam superficialmente as populações indígenas, enfatizando suas relações com os europeus; 4) arrolam e relatam as primeiras vilas fundadas; 5) analisam a presença da Matte Laranjeira na região; 6) tecem comentários sobre a divisão do estado; 7) descrevem a criação de novos municípios, indicando perspectivas de progresso e desenvolvimento; 8) dão grande destaque ao conflito com o Paraguai, principalmente no que diz respeito aos episódios que ocorreram no sul de Mato Grosso em fins de 1864 (2002, p. 76).

Ainda de acordo com Squinelo (2002, p. 124), a produção regional privilegiou, no contexto da Guerra do Paraguai, o episódio da retirada da Laguna, pois as operações da Guerra do Paraguai e da retirada ocorreram em Mato Grosso do Sul. Porém, ao procederem a escrita da história, elegeram as "fontes tradicionais", como as obras de Alfredo d'Escragnolle Taunay e Virgílio Corrêa Filho. Esse tipo de escrita prevalece, ainda, na extensa produção do Instituto Histórico e Geográfico de Mato Grosso e de Mato Grosso do Sul.

A visão épica e romanceada criada em torno da retirada da Laguna por Taunay levou muitos escritores, sobretudo os me- morialistas, a gestarem uma história ligada aos desígnios de uma elite dominante, bem como à figura de heróis e episódios grandiosos, na qual não há espaço para temas tidos como "menores" ou os ligados ao que alguns estudiosos denominam de "história vista de baixo".

Em 1991, foi publicada, pelo Instituto Histórico e Geográfico de Mato Grosso do Sul, com patrocínio do Estado, a obra História de Mato Grosso do Sul, de autoria de Hildebrando Campestrini e Acyr Vaz Guimarães. Atualmente está na sétima reedição e constituiu-se como a história oficial, sendo distribuída nas escolas e utilizada como bibliografia básica em concursos públicos. Os autores assumiram a tarefa de construir uma história oficial para Mato Grosso do Sul, de recriar seu passado, de solidificar os mitos de fundação e de ordenar os fatos até então dispersos, de trazer à existência essa nova região e forjar a identidade regional. Os fatos foram encadeados de forma a justificar a existência de Mato Grosso do Sul desde o século XVIII, bem como de sul-mato-grossenses. Assim, os autores conferem uma antiguidade, supostamente imemorial, como a de que Mato Grosso do Sul sempre existiu, embora tenha sido criado em 1977. Esses discursos politicamente engajados, ao defenderem a região, estruturam o regionalismo, ao inventar a região Mato Grosso do Sul, ao forjar subjetividades e ao produzir diferenças, trazendo-as à existência.

Os contextos da Guerra do Paraguai são abordados na referida obra do quarto ao sexto capítulo, intitulados: A invasão do território, A reação brasileira e A reconstrução do território, respectivamente. $\mathrm{O}$ texto 
constrói datas cívicas e heróis sul-mato-grossenses e elege monumentos e lugares que faziam parte do patrimônio de Mato Grosso do Sul. Tecem fatos para serem rememorados, levando em consideração que os sul-mato-grossenses tinham um passado heroico para se orgulhar. Seus ascendentes eram valentes, bravos, corajosos, destemidos, temerários e patrióticos, pois detiveram os inimigos e defenderam o território brasileiro apesar das dificuldades enfrentadas, como a falta de munições e a escassez de mantimentos, doenças e reduzidos efetivos militares. Nessa narrativa, Antônio João, José Francisco Lopes, o guia Lopes, e o Cel. Carlos de Moraes Camisão foram eleitos heróis sul-mato-grossenses, assim como D. Senhorinha, que foi escolhida a mulher símbolo de Mato Grosso do Sul. Segundo Amarilha (2006, p. 186), Campestrini e Guimarães (1991) valorizaram a retirada da Laguna por considerá-la como o episódio mais épico, glorioso e heroico da guerra, e, também, porque se realizou em terras sul-mato-grossenses.

Após o término do conflito, os autores registram a reconstrução de Corumbá, Miranda, Nioaque e Coxim, a reorganização política e religiosa, a reabertura da navegação no rio Paraguai, a demarcação das fronteiras, a exploração da erva-mate e a chegada de "nova gente":

Após a guerra, com os antigos fazendeiros chegaram à Vacaria, ao baixio da serra e aos pantanais outros tantos, atraídos pela excelência das terras, pelo clima saudável, abundância de águas e viçosas pastagens, características divulgadas nas províncias vizinhas pelos remanescentes da retirada da Laguna (CAMPESTRINI; GUIMARÃES, 2002, p. 158).
Assim, terminado o conflito, iniciou uma conjuntura de progresso para a região, com o aumento demográfico e a retomada do crescimento econômico.

\section{0 projeto Trilha da Retirada da Laguna}

A criação do projeto Trilha da Retirada da Laguna está inserida no contexto político das eleições de 1998 para o governo estadual. Os resultados eleitorais mudaram o cenário político, pois grupos que se perpetuaram no poder desde a criação de Mato Grosso do Sul foram derrotados. Saíam do poder nomes como Marcelo Miranda e Pedro Pedrossian, que se revezaram durante as décadas de 1970 e 1980. Chegava ao governo estadual um novo partido, o Partido dos Trabalhadores, na figura de José Orcírio Miranda dos Santos. Ao assumir a gestão, no início de 1999, a Secretaria de Cultura, Esporte e Lazer e outros setores do governo, iniciaram as discussões para viabilizar projetos turísticos a fim de inserir o Mato Grosso do Sul no circuito turístico de visitação histórica.

Naquele contexto, em 24 de março de 1999, foi realizada uma reunião entre o Secretário de Estado de Cultura, Esporte e Lazer, Silvio Nucci, e outros estudiosos para apresentar ao secretário a trajetória que compõe o palco da retirada da Laguna, que foi apresentada por Krugerson de Mattos, capitão da reserva do Exército brasileiro (NUCCI, 2004, p. 2). A proposta era viabilizar um projeto turístico de reconstituição do percurso realizado pela retirada.

O projeto foi apoiado, no decorrer das últimas décadas, por várias instâncias do governo estadual, por outras instituições, 
tais como o Exército, o Instituto Histórico e Geográfico de Mato Grosso do Sul, o Instituto do Patrimônio Histórico e Artístico Nacional e o Conselho Internacional de $\mathrm{Mu}$ seus. Assim, o projeto Trilha da Retirada da Laguna adequava-se a múltiplos interesses.

Outro projeto desenvolvido no âmbito estadual somou-se ao da trilha. Maria Margareth Escobar Ribas, diretora da $11^{\text {a }}$ Sub-regional do Instituto do Patrimônio Histórico e Artístico Nacional, Seção de Mato Grosso do Sul, planejou, em 2003, tombar a paisagem natural do espaço em que se desenrolou a retirada da Laguna.

Embora alguns estudiosos já viessem levantando algumas questões acerca da importância da rota da retirada da Laguna para fomentar o turismo, somente no novo governo, via Secretaria de Cultura, Esporte e Lazer, foi viabilizada a elaboração de um projeto para consolidar a iniciativa. A apropriação da Guerra do Paraguai nessa conjuntura política esteve associada ao novo grupo político e seu interesse em perpetuar-se no poder. $\mathrm{Ou}$ seja, a memória da guerra não se configura apenas como uma memória cívica e patriótica, mas também econômica e política.

De acordo com o secretário de Turismo e o secretário de Cultura e Lazer do estado de Mato Grosso do Sul, Silvio Di Nucci, o governo estadual

[...] ofereceu suporte para o lançamento das ações e apoio quanto a publicação da revista distribuída no evento, referindo-se a temática da Retirada, [...] abordando questões relativas a execução do projeto em pauta (NUCCI, 2004, p. 1).

Os municípios que seriam envolvidos eram os de "Anastácio, Aquidauana, Bela
Vista, Guia Lopes da Laguna, Nioaque em Mato Grosso do Sul e Bella Vista Norte/Paraguai". Apesar disso, o projeto não definia qual seria a participação desses municípios (NUCCI, 2004, p. 2).

O projeto da Trilha da Retirada da Laguna e outros que se referem à retirada foram articulados pelos municípios já citados tendo como justificativas dois pressupostos: a) a configuração e/ou consolidação de uma identidade sul-mato-grossense ligada ao episódio da Guerra do Paraguai e, ao mesmo tempo, à retirada da Laguna; b) o intuito de implantar o turismo cultural e/ ou contemplativo como mecanismo de desenvolver tais municípios, gerando emprego e renda.

Nesse contexto, torna-se imperativo o apoio e o incentivo do governo estadual aos projetos mencionados, na medida em que se consolida a construção de uma história ligada aos desígnios de um grupo que pretendia se perpetuar no poder. Por isso, apropriam-se da História para reforçar uma ideologia do estado. Vale ressaltar que a memória da guerra em Mato Grosso do Sul não é construída de forma linear e cumulativa, ao contrário, é edificada com interrupções, sendo resgatada nos contextos em que pode servir à determinada ideologia. Então, inversamente ao que insistem em afirmar, que as memórias da guerra e da retirada caracterizam-se como uma "memória de cunho patriótico", acreditamos que seja a memória de uma "conotação política" singular.

Em suma, em diferentes conjunturas históricas, os contextos da Guerra do Paraguai e da retirada da Laguna foram e continuam sendo apropriados e reapropriados de acordo com interesses e projetos políticos de 
diferentes grupos que assumem o governo estadual, mantendo a memória desses episódios viva, estabelecendo uma conexão entre o passado e o presente e definindo como sendo a identidade sul-mato-grossense.

\section{Abstract}

This article focuses on the senses of the celebrations about the Paraguayan War (1864-1870) in Mato Grosso and Mato Grosso do Sul. To this end, we analyzed the debates concerning the memory, the memory spaces and celebrations; particular, we list as a guideline of our reflections the episode called Laguna Withdrawal (1865-1867), considered the Paraguay War and secondary scenario occurred in Mato Grosso territory. We are interested in, especially reflect on the impact of this event in the formation of memory and Mato Grosso do Sul identity.

Keywords: Celebrations. Paraguayan War. Laguna Withdrawal.

\section{Resumen}

Este artículo examina el significado de las celebraciones sobre la Guerra del Paraguay (1864-1870) en Mato Grosso y Mato Grosso do Sul; para esto nos referimos a las discusiones relativas a la memoria, a los espacios de memoria y celebraciones; en particular, enumeramos como guía de nuestras reflexiones el episodio llamado Retirada de Laguna (1865-1867), considerado como escenario secundário durante la Guerra del Paraguay y se produjo en territorio de Mato Grosso. Nos interesa, sobre todo reflexionar sobre el impacto de este evento en la formación de la memoria y la identidad de Mato Grosso del Sur.

Palabras clave: Celebraciones. Guerra del Paraguay. Retirada de Laguna.

\section{Notas}

1 ALMA DO BRASIL. Disponível em: <https:// www.youtube.com/watch? $\mathrm{v}=\mathrm{m}-\mathrm{f} 6 \mathrm{k} 1 \mathrm{dlzwI}>$. Acesso em: 25 mar. 2015.

2 Ofício $\mathrm{n}^{\circ} 31$, de 23 de julho de 1923, do intendente Arlindo de Andrade. In: ARCA, caixa 4, livro 76-A, p. 4 e 4-verso.

\section{Referências}

ALAMBERT, Francisco. Civilização e barbárie, história e cultura. Representações culturais e projeções da "Guerra do Paraguai" nas crises do Segundo Reinado e da Primeira República. 1999. Tese (Doutorado em História Social) Faculdade de Filosofia, Letras e Ciências Humanas, Universidade de São Paulo, São Paulo, 1999.

AMARILHA, Carlos Magno Mieres. Os intelectuais e o poder: história, divisionismo e identidade em MS. 2006. 252f. (Mestrado em História) - Faculdade de Ciências Humanas, Universidade Federal da Grande Dourados, Dourados, 2006.

CAMPESTRINI, Hildebrando; GUIMARÃES, Acyr V. História de Mato Grosso do Sul. Campo Grande: Instituto Histórico e Geográfico MS, 2002.

CANCLINI, Néstor García. Culturas híbridas. São Paulo: Edusp, 1998.

CARDOSO, Athos Eichler. Introdução. In: TAUNAY, Alfredo d'Escragnolle. A retirada da Laguna: episódio da Guerra do Paraguai. Brasília: Senado Federal, 2011. 
CONNERTON, Paul. Como as sociedades recordam. Tradução de Maria Manuela Rocha. 2. ed. Oeiras: Celta, 1999.

CORRÊA FILHO, Virgílio. História de Mato Grosso. Rio de Janeiro: Instituto Nacional do Livro, 1969.

CUNHA, Euclides da. Os sertões. Rio de Janeiro: Record, 2000.

HOBSBAWM, Eric; RANGER, Terence. $A$ invenção das tradições. Rio de Janeiro: Paz e Terra, 1994.

NORA, Pierre. Entre a memória e história. A problemática dos lugares. Tradução de Yara Aun Khoury. Projeto História, São Paulo, v. 10, p. 7-28, dez. 1993.

NUCCI, Silvio Di. OF/GAB/SEC n ${ }^{\circ}$ 0855/2004, de 2 de dezembro de 2004. Campo Grande, MS, 2004. 2 p.

PROST, Antonie. Les monuments aux morts culte républicain? Culte civique? Culte patriotique? In: NORA, Pierre. Les lieux de mémoire. Paris: Gallimard, [19--?]. p. 195-225. (La Republique, v. 1).

SQUINELO, Ana Paula. A Guerra do Paraguai ontem e hoje: Mato Grosso e Mato Grosso do Sul (1868-2003). 2006. Tese (Doutorado em História Social) - Faculdade de Filosofia, Letras e Ciências Humanas, Universidade de São Paulo, São Paulo, 2006.

. A guerra do Paraguai, essa desconhecida. Ensino, memória e história de um conflito secular. Campo Grande: UCDB, 2002.

TAUNAY, Alfredo d'Escragnolle. A missão artística de 1816. Brasília: UnB, 1983.

A retirada da Laguna: episódio da Guerra do Paraguai. Tradução e organização de Sérgio Medeiros. São Paulo: Companhia das Letras, 1997. (Retratos do Brasil).

Campanha de Matto Grosso. Scenas de viagem. 2. ed. São Paulo: Livraria do Globo; Irmãos Marrano, 1923.
- Cartas da campanha. A cordilheira. Agonia de Lopez (1868-1870). São Paulo: Melhoramentos; Rio de Janeiro: Cayeiras, 1922.

Cartas da campanha de Matto Grosso (1865-1866). Rio de Janeiro: Biblioteca Militar, 1944.

Céus e terras do Brasil. 9. ed. Viagens de outrora. 3. ed. Paisagens brasileiras. 2. ed. São Paulo: Melhoramentos, 1948. Volume único.

Diário do Exército (1869-1870). A campanha da Cordilheira e de Campo Grande a Aquidabã. Rio de Janeiro: Biblioteca do Exército, 1958.

. Dias de guerra e de sertão. 3. ed. São Paulo: Melhoramentos; Rio de Janeiro: Cayeiras, 1927. Ilustrado.

Em Mato Grosso invadido (1866-1867). São Paulo: Melhoramentos; Rio de Janeiro: Cayeiras, 1929.

. Scenas de viagem: exploração entre os rios Taquary e Aquidauana no districto de Miranda. Rio de Janeiro: Tipografia Americana, 1868.

. Viagens de Outr'ora. 2. ed. São Paulo: Melhoramentos; Rio de Janeiro: Cayeiras, 1921. Visões do sertão. 2. ed. São Paulo: Melhoramentos; Rio de Janeiro: Cayeiras, 1928.

ZORZATO, Osvaldo. Conciliação e identidade: considerações sobre a historiografia de Mato Grosso. 1998. Tese (Doutorado em História Social) - Faculdade de Filosofia, Letras e Ciências Humanas, Universidade de São Paulo, São Paulo, 1998. 